Check for updates

Cite this: RSC Adv., 2019, 9, 32691

Received 12th May 2019

Accepted 25th September 2019

DOI: $10.1039 / c 9 r a 03556 g$

rsc.li/rsc-advances

\section{Effect of heat treatment under vacuum on structure and visible-light photocatalytic activity of nano- $\mathrm{TiO}_{2}$}

\author{
Zhengyuan Gao, ${ }^{a}$ Pengfei Sun, ${ }^{a}$ Yiliu Fang, ${ }^{a}$ Chuanqiang Li, (D) ${ }^{* b}$ Xiaoya Yuan, ${ }^{b}$ \\ Xuxu Zheng ${ }^{\mathrm{ab}}$ and Jiacheng Gaoc
}

Nano- $-\mathrm{TiO}_{2}$ is known as a photocatalyst with high catalytic activity. However, it should be emphasized that the bandgap of nano- $\mathrm{TiO}_{2}$ is wide, which limits its photocatalytic efficiency in response to visible light and thus hinders its potential application. Improving the photocatalytic activity of nano- $\mathrm{TiO}_{2}$ under visible light by the strategy of heat treatment under vacuum was investigated in this study. The structure and photocatalytic activity of nano- $\mathrm{TiO}_{2}$ before and after heat treatment under vacuum were compared and analyzed by XRD, TEM, HRTEM, XPS and UV-Vis-NIR, respectively. The results show that oxygen vacancies were introduced into the crystal structure of nano- $\mathrm{TiO}_{2}$ to change its inherent energy band structure. Particularly, the samples after heat treatment under vacuum exhibited high photocatalytic activity under visible light. In addition, the formation mechanism of non-stoichiometric compound $\mathrm{TiO}_{2-x}$ and the mechanism of oxygen vacancy defects to expand the wavelength of light that nano- $\mathrm{TiO}_{2}$ absorbs to the visible portion of the spectrum have also been addressed in this paper

\section{Introduction}

The discovery made by Fujishima and Honda in 1972 indicated that water and other substances could be decomposed by a $\mathrm{TiO}_{2}$ single-crystal electrode under visible light. ${ }^{1}$ This finding provided a new application field for $\mathrm{TiO}_{2}$ based photocatalysts. In recent years, the research on photocatalysis technology of $\mathrm{TiO}_{2}$ has attracted increasing attention from scientific communities due to its appealing advantages such as the high catalytic oxidation activity, the fast photocatalysis degradation reaction, the high photocatalytic activity, and so on. ${ }^{2,3}$ Thus, $\mathrm{TiO}_{2}$ based photocatalysts have great potential for applications in a wide range of areas, for example, environmental management, ${ }^{4}$ development of new energy, ${ }^{5-9}$ air purification, ${ }^{\mathbf{1 0}, 11}$ sewage treatment, ${ }^{\mathbf{1 2}}$ self-cleaning ceramics, $^{\mathbf{1 3}, \mathbf{1 4}}$ sterilization material, ${ }^{15-18}$ photoelectric conversion, ${ }^{19,20}$ etc. However, the application of $\mathrm{TiO}_{2}$ based photocatalysts is still limited due to the following two aspects. Firstly, the wide band gap of $\mathrm{TiO}_{2}$ limits its photocatalytic efficiency in response to solar radiation (only UV light, accounting for $\sim 5 \%$ of the solar spectrum can be utilized). ${ }^{21}$ Secondly, it is easy for photoinduced electron hole pairs to recombine, leading to low photocatalytic performance

${ }^{a}$ School of Mechatronics and Automotive Engineering, Chongqing Jiaotong University, Chongqing, China, 400074

${ }^{b}$ School of Materials Science and Engineering, Chongqing Jiaotong University, Chongqing, China, 400074. E-mail: lichuanqiang_cn@163.com

${ }^{c}$ School of Materials Science and Engineering, Chongqing University, Chongqing, China, 400044 and then low rate of degradation to contaminants. To this end, considerable efforts have been made to improve the photocatalytic efficiency of $\mathrm{TiO}_{2}$ in response to visible light. The existing methods mainly include doping, ${ }^{22-29}$ compound semiconductor, ${ }^{30}$ noble metal deposition, ${ }^{31}$ dye sensitization, ${ }^{32}$ and surface pretreatment by introducing structural defects. ${ }^{33-35}$ The crystal structure and band structure of nano- $\mathrm{TiO}_{2}$ could be changed upon using ion doping by ion implantation and chemical doping, and also the photocatalytic activity of $\mathrm{TiO}_{2}$ can be improved by the methods of dye sensitization or compound semiconductor. However, those methods have many disadvantages, for example, the thermal stability is poor, the doped ion is easy to become the composite center of electron hole pairs, and the optical absorption efficiency is low. ${ }^{36}$ It is thus highly desired to develop an effective method to improve the photocatalytic efficiency of $\mathrm{TiO}_{2}$ in response to visible light, but not with the drawbacks inherent in the aforementioned existing methods. The effort in this paper is to provide an effective solution to such problem.

Of particular interest in this paper is to improve the photocatalytic efficiency of $\mathrm{TiO}_{2}$ in response to visible light by heat treatment in vacuum. On the basis of non-stoichiometric compounds, we tried to introduce the oxygen vacancy into the crystal structure of nano- $\mathrm{TiO}_{2}$ to change its inherent energy band structure. As a result, it can absorb visible light over a certain range of wavelength. In addition, we also investigated the mechanism of photocatalytic activity under visible light on the basis of lattice imperfections and energy band of semiconductor to propose a modified technology that is effective to 
improve the photocatalytic efficiency of $\mathrm{TiO}_{2}$ in response to visible light.

\section{Experimental}

To study the effect of heat treatment in vacuum on structure and photocatalytic activity of nano- $\mathrm{TiO}_{2}$ under visible light, the nano- $\mathrm{TiO}_{2}$ anatase powders (MTI, $\sim 6.40 \mathrm{~nm}$ in size, $99.99 \%$ purity) was taken as the test subjects. The $\mathrm{TiO}_{2}(0.5 \mathrm{~g})$ nanoparticles were placed into corundum crucible to be annealed in VSFV-30 type vacuum furnace. Heat treatment temperatures in this process were taken as $400{ }^{\circ} \mathrm{C}$ and $1000{ }^{\circ} \mathrm{C}$, respectively, with a holding time of $40 \mathrm{~min}$. The samples were naturally cooled to room temperature in furnace. Before the $\mathrm{TiO}_{2}$ nanoparticles were heated, the vacuum furnace was pumped below the degree of $\sim 1.0 \times 10^{-1} \mathrm{~Pa}$. During the whole heating, heat preservation, and cooling process, the vacuum of furnace was maintained at $\sim 1.0 \times 10^{-1} \mathrm{~Pa}$ by pumping vacuum continuously. Then the samples of $\mathrm{TiO}_{2}$ nanoparticles was taken out until the temperature is cooled to room temperature.

The phase purity of the samples was verified by powder X-ray diffraction (PXRD) (Bruker D8 ADVANCE AXS) using CuK $\alpha$ radiation $(\lambda=1.5418 \AA)$ in the range $2 \theta=10-90^{\circ}$. The size and crystal structure of $\mathrm{TiO}_{2}$ samples analyzed using transmission electron microscopy (TEM) (Tecnai G2 F20) at an acceleration voltage of $200 \mathrm{kV}$. Future analysis was carried out using highresolution X-ray photoelectron spectroscopy (XPS) (Gammadata-Scienta SES 2002) and UV-Vis-NIR Spectrophotometer (Model UV-3101PC Shimadzu) with wavelength ranging from 200 to $700 \mathrm{~nm}$.

The photocatalytic performance of the catalysts were assessed by photo-degradation of methyl orange (MO) solution under visible light. All the experiments were carried out using a BILON-CHX-V photoreactor (Shanghai Bilon Instruments Manufacture Co., Ltd., Shanghai, China) and a $500 \mathrm{~W}$ xenon lamp with working current $5 \mathrm{~A}$. The intensity of irradiation was $100 \mathrm{~mW} \mathrm{~cm} \mathrm{~cm}^{-2} 5 \mathrm{mg}$ of catalysts were mixed with $40 \mathrm{~mL}$ of $\mathrm{MO}$ solution (20 $\left.\mathrm{mg} \mathrm{L}^{-1}\right)$ and kept stirring in the dark for $1 \mathrm{~h}$ to establish the adsorption equilibrium. During the irradiation, $3 \mathrm{~mL}$ of the reaction solution was withdrawn at certain time intervals and centrifuged to remove the catalysts. The decolorization efficiency was determined by the concentration of MO studied by the spectrophotometer (AOE, Shanghai, China) at the maximum absorption wavelength of $464 \mathrm{~nm} \cdot{ }^{37-39}$ The degradation rate was calculated by the following formula: degradation rate $(\%)=100 \times\left(C_{0}-C_{t}\right) / C_{0}$. Where $C_{0}$ is the initial concentration of $\mathrm{MO}\left(\mathrm{mg} \mathrm{L}^{-1}\right) ; C_{t}$ is the concentration of $\mathrm{MO}$ in another given irradiation time $\left(\mathrm{mg} \mathrm{L}^{-1}\right)$.

\section{Results and discussion}

The effects of heat treatment in vacuum on structure of nano$\mathrm{TiO}_{2}$

The XRD pattern of nano- $\mathrm{TiO}_{2}$ after treatment in vacuum is represented in Fig. 1. Analysis of testing results shows that the structure of $\mathrm{TiO}_{2}$ nanoparticles still belongs to anatase after heat treatment in vacuum at $400{ }^{\circ} \mathrm{C}$, with the grain size being

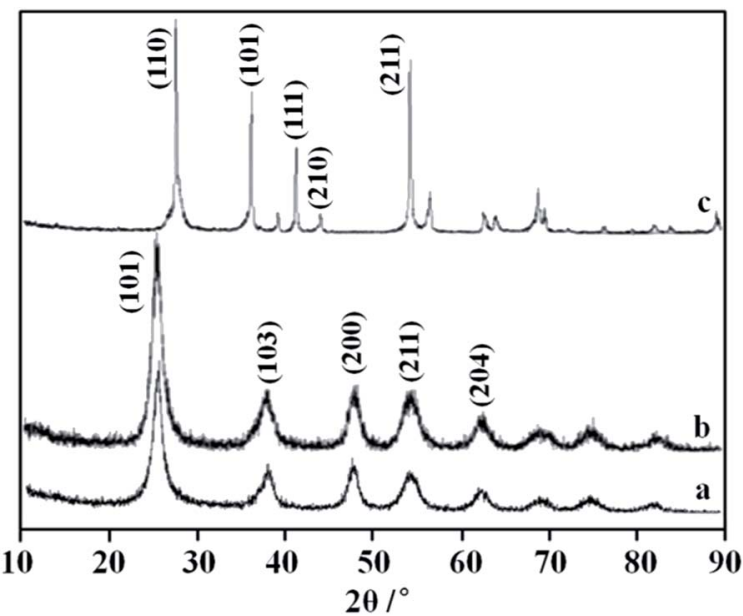

Fig. 1 XRD pattern of nano- $\mathrm{TiO}_{2}$ after treatment in vacuum ((a) original anatase, (b) $400{ }^{\circ} \mathrm{C} \times 40 \mathrm{~min}$, (c) $1000^{\circ} \mathrm{C} \times 40 \mathrm{~min}$ ).

about $8.30 \mathrm{~nm}$. The structure of nano- $\mathrm{TiO}_{2}$ is transferred to the structure of rutile after heat treatment in vacuum at $1000{ }^{\circ} \mathrm{C}$, with the grain size being about $50 \mathrm{~nm}$. Compared with the general heat treatment process not in vacuum, where the grain sizes of nano- $\mathrm{TiO}_{2}$ after heat treatment in box-type furnace at $400{ }^{\circ} \mathrm{C}$ and $1000{ }^{\circ} \mathrm{C}$ are $12.6 \mathrm{~nm}$ and $63.7 \mathrm{~nm}$ respectively, under the same temperature condition the growth tendency of grain can be decreased with the heat treatment in vacuum.

The TEM pictures of nano- $\mathrm{TiO}_{2}$ samples after heat treatment in vacuum under $400{ }^{\circ} \mathrm{C}$ and $1000{ }^{\circ} \mathrm{C}$ are shown in Fig. 2(b) and (c), respectively. It indicates that the $\mathrm{TiO}_{2}$ nanoparticles after heat treatment in vacuum at $400{ }^{\circ} \mathrm{C}$ consist of particles with grain size of $10 \mathrm{~nm}$ and the particles treated at $1000{ }^{\circ} \mathrm{C}$ have a grain size of $50 \mathrm{~nm}$. Both nanoparticles heat treated in vacuum are nearly spherical and homogenous.

The main text of the article should appear here with headings as appropriate.

The HRTEM pictures of nano- $\mathrm{TiO}_{2}$ samples after heat treatment in vacuum at $400{ }^{\circ} \mathrm{C}$ and $1000{ }^{\circ} \mathrm{C}$ are shown in Fig. 3(a) and (b) respectively. The diffraction spots after Fourier transformation at $400{ }^{\circ} \mathrm{C}$ and $1000{ }^{\circ} \mathrm{C}$ are shown in the bottom right corner of Fig. 3(a) and (b) respectively. The results in Fig. 3 have been listed in Table 1.

The comparison between the experimental data and the theoretical values of anatase $\mathrm{TiO}_{2}$, which can be seen from Table 1 , shows that the experimental results basically agree with theoretical values. Combined with XRD analysis, one can see that the samples after heat treatment in vacuum at $400{ }^{\circ} \mathrm{C}$ are anatase $\mathrm{TiO}_{2}$, in which the crystal face involved in the experiment is (002) facet and (101) facet, respectively. Note that the anatase type $\mathrm{TiO}_{2}$ has tetragonal crystal structure, according to the formula of the interplanar spacing of tetragonal system in crystal, namely,

$$
\frac{1}{d^{2}}=\frac{h^{2}+k^{2}}{a^{2}}+\frac{l^{2}}{c^{2}}
$$



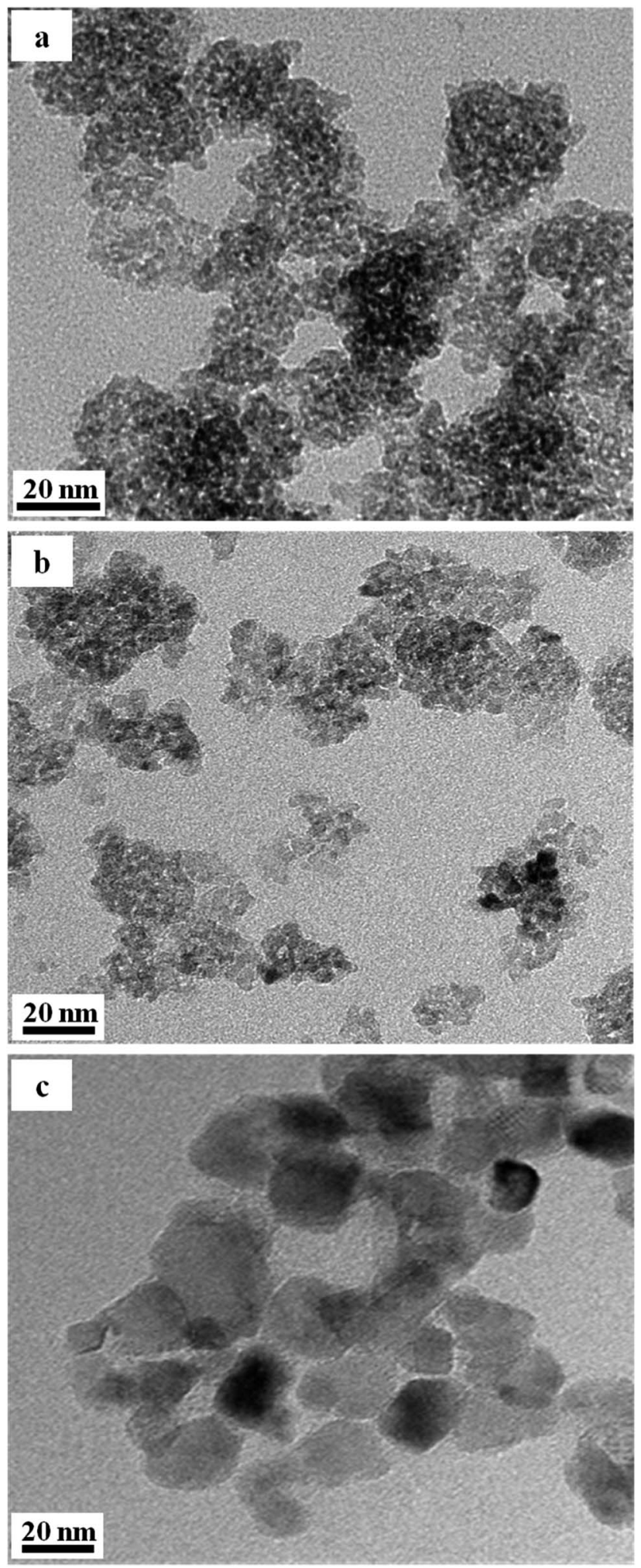

Fig. 2 TEM pictures of sample treated in vacuum ((a) original anatase, (b) $400{ }^{\circ} \mathrm{C} \times 40 \mathrm{~min}$, (c) $1000^{\circ} \mathrm{C} \times 40 \mathrm{~min}$ ).

the lattice constant ratio $c / a$ can be calculated by the two sets of interplanar spacing $(d)$ and the corresponding crystal index $(h k l)$. Using the $d$ and $(h k l)$ listed in Table 1, the lattice constant
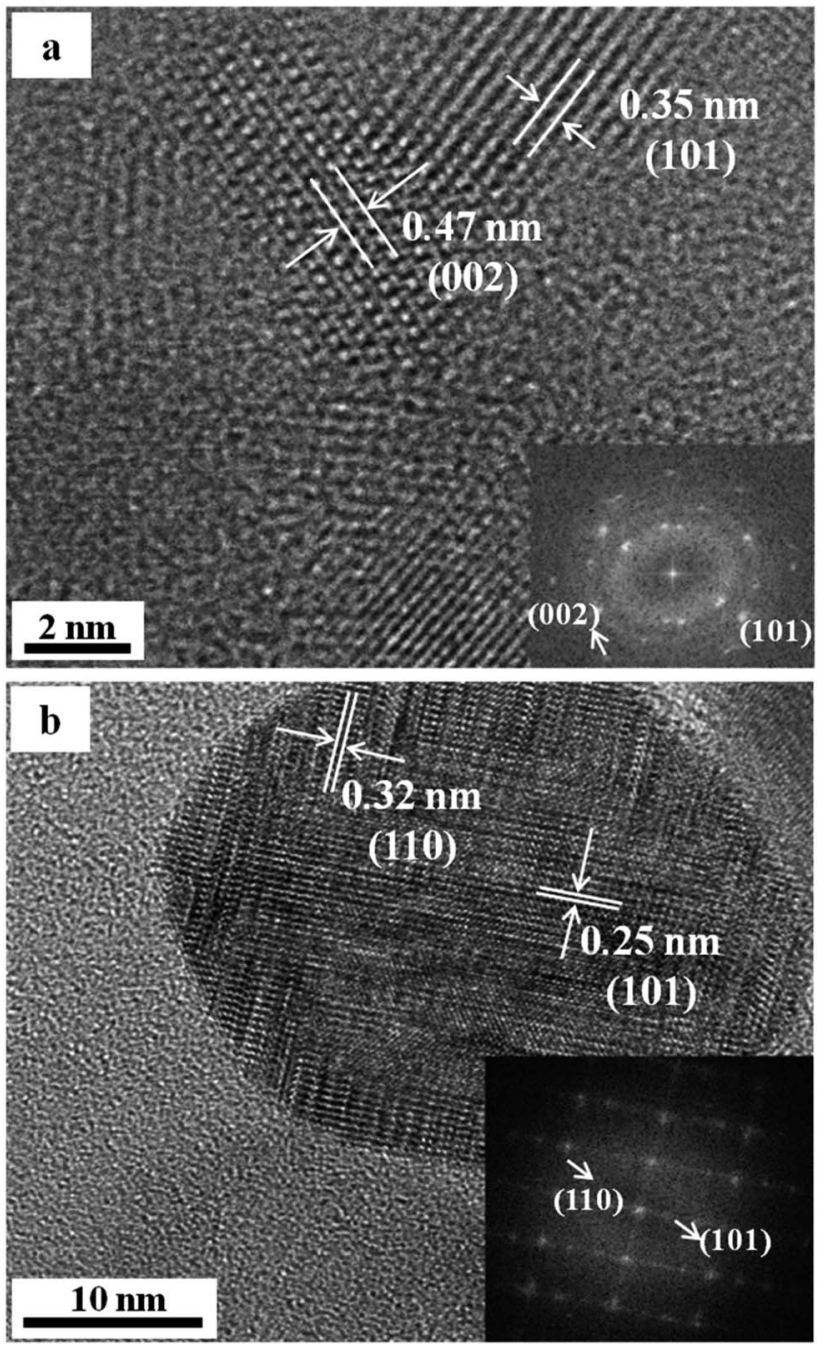

Fig. 3 HRTEM pictures of sample treated in vacuum ((a) $400{ }^{\circ} \mathrm{C} \times$ $40 \mathrm{~min}$, (b) $\left.1000^{\circ} \mathrm{C} \times 40 \mathrm{~min}\right)$.

ratio of the samples after heat treatment in vacuum at $400{ }^{\circ} \mathrm{C}$ was obtained as $c / a=2.4864$. While the lattice constant ratio of anatase nano- $\mathrm{TiO}_{2}$ heat treated in a box-type furnace (nonvacuum) at $400{ }^{\circ} \mathrm{C}$ is 2.5072 , with $c=9.49749$ and $a=$ 3.78811. Thus, the $c / a$ of the samples after heat treatment in vacuum decreased by $0.829 \%$ compared with that of the samples heat treated not in vacuum at the same temperature. Similarly, it can be calculated that the lattice constant ratio of the samples after heat treatment in vacuum at $1000{ }^{\circ} \mathrm{C}$ is $=0.6414$, which decreased by $0.419 \%$ by comparing with that of the samples not in vacuum at $1000{ }^{\circ} \mathrm{C}$. The decrease of $c / a$ may be due to the decrease of the lattice constant $c$ resulting from the formed during the vacuum heat treatment. The oxygen vacancies were formed owing to the diffusion of the oxygen atoms in the lattice of nano- $-\mathrm{TiO}_{2}$ into the vacuum atmosphere.

\section{Analysis of X-ray photoelectron spectroscopy (XPS)}

The composition of the surface element was obtained by fullspectrum scanning on the nano- $\mathrm{TiO}_{2}$ samples before and after 
Table 1 Information about the crystal structure of samples treated in vacuum

\begin{tabular}{llllll}
\hline & $d_{1}(\AA)$ & $d_{2}(\AA)$ & Ratio $\left(d_{1} / d_{2}\right)$ & Angle $\left({ }^{\circ}\right)$ & Temperature $\left({ }^{\circ} \mathrm{C}\right)$ \\
\hline Measured values & 4.69 & 3.5 & 1.34 & 68.7 & \\
Anatase $\mathrm{TiO}_{2}(h k l)$ & $4.75(002)$ & $3.51(101)$ & 1.35 & 68.3 & 90 \\
Measured values & 3.25 & 2.485 & 1.308 & 900 & 90
\end{tabular}

heat treatment in vacuum. The XPS spectrum results are represented in Fig. 4. It can be seen from Fig. 4 that the elements Ti and $\mathrm{O}$ are mainly contained in the nano- $\mathrm{TiO}_{2}$ samples before and after heat treatment in vacuum, as well as some small amounts of elements $\mathrm{N}$ and $\mathrm{C}$. The atomic percentage of $\mathrm{O} 1 \mathrm{~s}$ and $\mathrm{Ti} 2 \mathrm{P}$ of raw $\mathrm{TiO}_{2}$ and heat treated $\mathrm{TiO}_{2}$ in vacuum is listed in Table 2. The results show that the atomic ratio of $\mathrm{O} / \mathrm{Ti}$ is less than 2 after the heat treatment in vacuum, which confirms that oxygen vacancies were formed in the lattice as the oxygen atoms in the lattice of $\mathrm{TiO}_{2}$ diffuse to the vacuum. Furthermore, the intensity of the peak located at the binding energy of $531.1 \mathrm{eV}$ are increased obviously for the $\mathrm{TiO}_{2}$ samples after heat treatment in vacuum, indicating that the content of $\mathrm{O}^{2-}$ ions in the oxygen-deficient regions were increased..$^{20}$ The result also demonstrate that the oxygen vacancies were formed in the $\mathrm{TiO}_{2}$ matrix after heat treatment in vacuum.
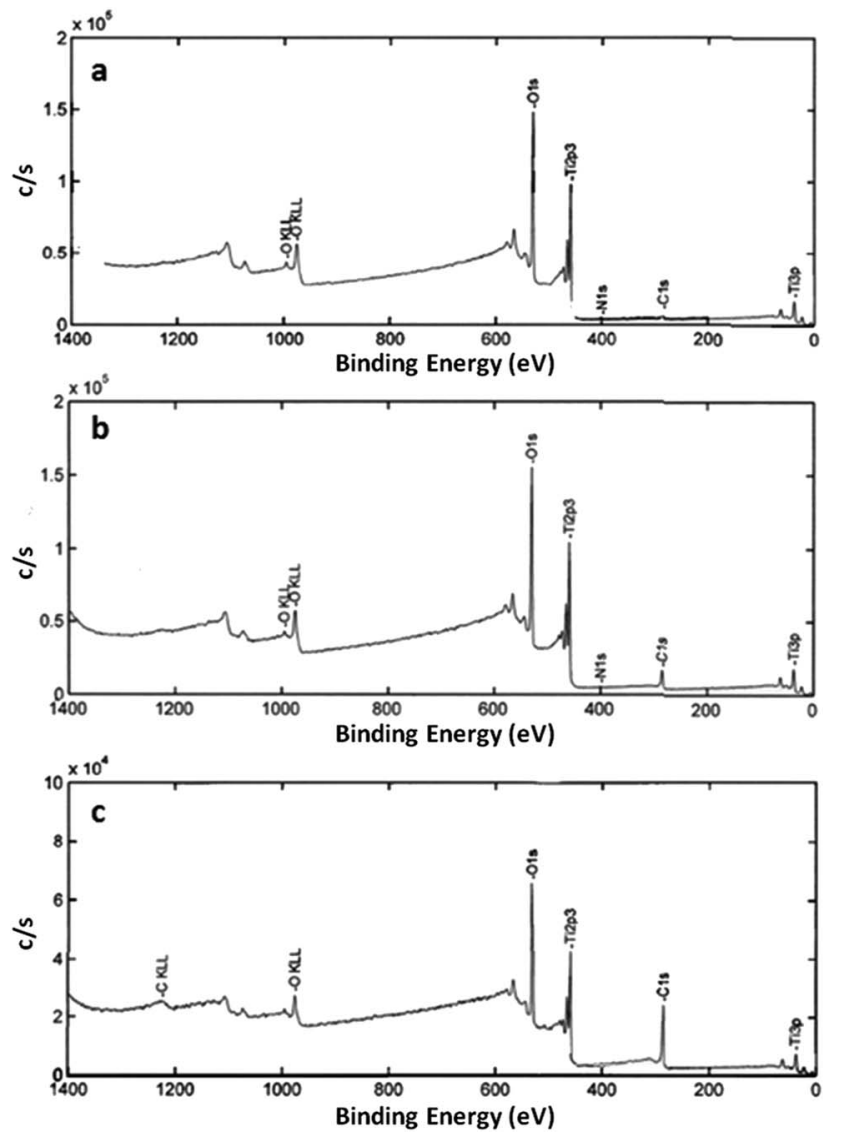

Fig. 4 XPS spectra for nano- $\mathrm{TiO}_{2}$ before and after treatment in vacuum ((a) raw anatase, (b) $400{ }^{\circ} \mathrm{C} \times 40 \mathrm{~min}$, (c) $1000^{\circ} \mathrm{C} \times 40 \mathrm{~min}$ ).
Table 2 Atomic percentage and ratio of elements $\mathrm{O}$ and $\mathrm{Ti}$

\begin{tabular}{llll}
\hline & $\mathrm{O} 1 \mathrm{~s}$ & $\mathrm{Ti} 2 \mathrm{P}$ & $\mathrm{O} / \mathrm{Ti}$ \\
\hline Original anatase $\mathrm{TiO}_{2}$ & 54.12 & 27.06 & 2 \\
$\mathrm{TiO}_{2}$ modified at $400{ }^{\circ} \mathrm{C}$ & 49.077 & 25.38 & 1.9337 \\
$\mathrm{TiO}_{2}$ modified at $1000{ }^{\circ} \mathrm{C}$ & 32.227 & 16.62 & 1.9390
\end{tabular}

To further study the chemical valence of element Ti, the Ti $2 \mathrm{p}$ of the samples before and after heat treatment in vacuum was scanned in narrow zone. The XPS spectrum result is represented in Fig. 5. In the XPS database, for $\mathrm{Ti}^{4+}$ ions the binding energies corresponding to the photoelectron spectrums of $\mathrm{Ti} 2 \mathrm{p}_{1 / 2}$ and $\mathrm{Ti}$ $2 \mathrm{p}_{3 / 2}$ are $464.5 \mathrm{eV}$ and $458.8 \mathrm{eV}$, respectively. For the compounds of $\mathrm{Ti}$ in different valence state, there is no change in the values of binding energy of Ti $2 p_{1 / 2}$, while the values of binding energy of Ti $2 \mathrm{p}_{3 / 2}$ are different. For example, the binding energy values corresponding to the $\mathrm{Ti} 2 \mathrm{p}_{3 / 2}$ lines of $\mathrm{TiO}_{1.5}$, TiO, and $\mathrm{Ti}$ are $456.1 \mathrm{eV}, 455.1 \mathrm{eV}$, and $454 \mathrm{eV}$, respectively. ${ }^{40}$ It thus can be concluded that the lower the chemical valence of Ti ions, the smaller the binding energy of corresponding $\mathrm{Ti} 2 \mathrm{p}_{3 / 2}$ lines. From Fig. 5 we see that the binding energy value of Ti $2 \mathrm{p}_{3 / 2}$ lines of nano- $\mathrm{TiO}_{2}$ before heat treatment in vacuum is $459.01 \mathrm{eV}$. The binding energy values of $\mathrm{Ti} 2 \mathrm{p}_{3 / 2}$ lines of nano- $\mathrm{TiO}_{2}$ after heat treatment in vacuum at $400{ }^{\circ} \mathrm{C}$ and $1000{ }^{\circ} \mathrm{C}$ are reduced to $457.6 \mathrm{eV}$ and $458.2 \mathrm{eV}$, respectively. The decrease in binding energy indicates that the chemical valence of some atoms $\mathrm{Ti}$ in

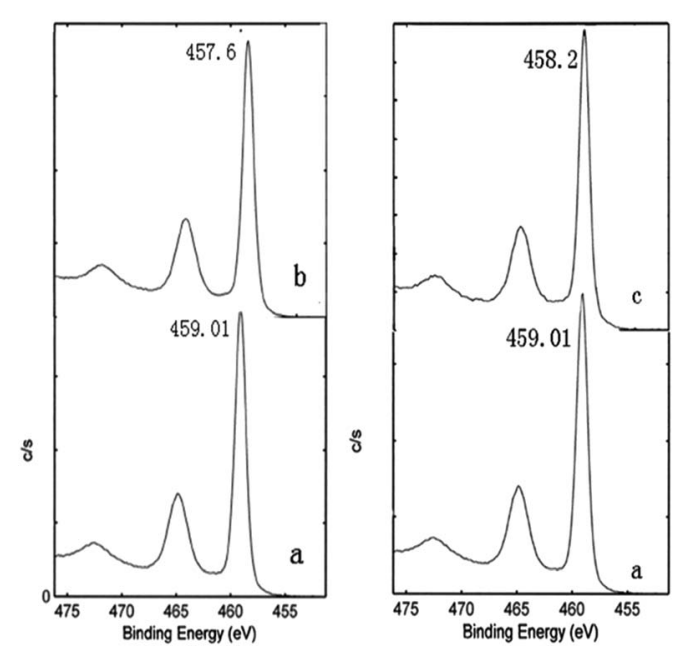

Fig. 5 XPS spectra of Ti $2 \mathrm{p}$ for nano- $\mathrm{TiO}_{2}$ before and after treatment in vacuum ((a) raw anatase $\mathrm{TiO}_{2}$, (b) $400{ }^{\circ} \mathrm{C}$, (c) $1000^{\circ} \mathrm{C}$ ). 
the modified samples has been changed, and there exist the $\mathrm{Ti}^{3+}$ ions.

\section{Analysis of ultraviolet-visible diffuse reflectance absorption spectrum}

The diffuse reflectance absorption spectrum results of nano$\mathrm{TiO}_{2}$ powders before and after heat treatment in vacuum are represented in Fig. 6 . From Fig. 6 we see that the light region of the absorption of the nano- $\mathrm{TiO}_{2}$ powders before heat treatment in vacuum is limited to the ultraviolet region $(10-400 \mathrm{~nm})$. On the contrary, the nano- $\mathrm{TiO}_{2}$ powders after the heat treatment in vacuum is extended to the visible light region. Specifically, after heat treatment in vacuum the optical absorption threshold wavelength of the samples modified at $400{ }^{\circ} \mathrm{C}$ was shifted to $480 \mathrm{~nm}$, and that modified at $1000{ }^{\circ} \mathrm{C}$ was shifted to $600 \mathrm{~nm}$, indicating that the wavelengths of light the nano- $\mathrm{TiO}_{2}$ absorbs was shifted to the visible portion $(380-780 \mathrm{~nm})$ of the spectrum after heat treatment in vacuum.

\section{The effect of heat treatment in vacuum on photocatalytic activity of nano- $\mathrm{TiO}_{2}$ under visible light}

The relationship between the time and the degradation rate of methyl orange solution degraded by samples before and after heat treatment in vacuum is shown in Fig. 7(a). It can be seen from Fig. 7(a) that the nano- $\mathrm{TiO}_{2}$ after heat treatment in vacuum has photocatalytic activity under visible light. Besides, the nano- $\mathrm{TiO}_{2}$ powders treated at $400{ }^{\circ} \mathrm{C}$ exhibited the best photocatalytic activity under visible light. The degradation rate of nano- $\mathrm{TiO}_{2}$ powders treated at $400{ }^{\circ} \mathrm{C}$ after $3 \mathrm{~h}$ of light reaches $81.233 \%$, the degradation rate of the samples heat treated in vacuum at $1000{ }^{\circ} \mathrm{C}$ is only $40.055 \%$ after $3 \mathrm{~h}$ of light. This is likely related to particle size and crystal structural difference.

The photocatalytic data was future analyzed by the first-order kinetic model. As shown in Fig. 7(b), the first-order kinetic model fitted well with experimental data. The values of rate constant $\left(k_{\mathrm{e}}\right)$ and regression coefficients $\left(R^{2}\right)$ were listed in Table 3 . The values of $R^{2}$ were all higher than 0.900 , which indicated the

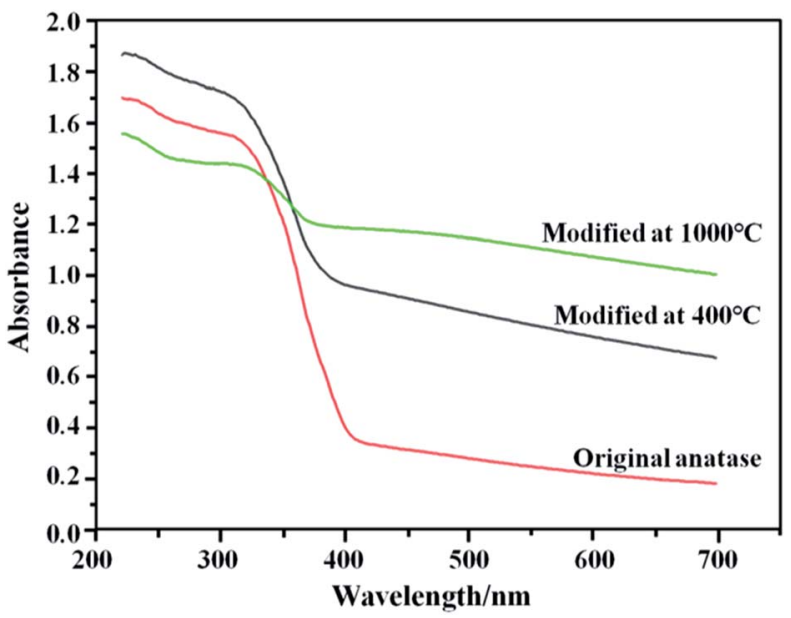

Fig. 6 UV-Vis diffusive reflectance absorption spectra of samples before and after treatment in vacuum.
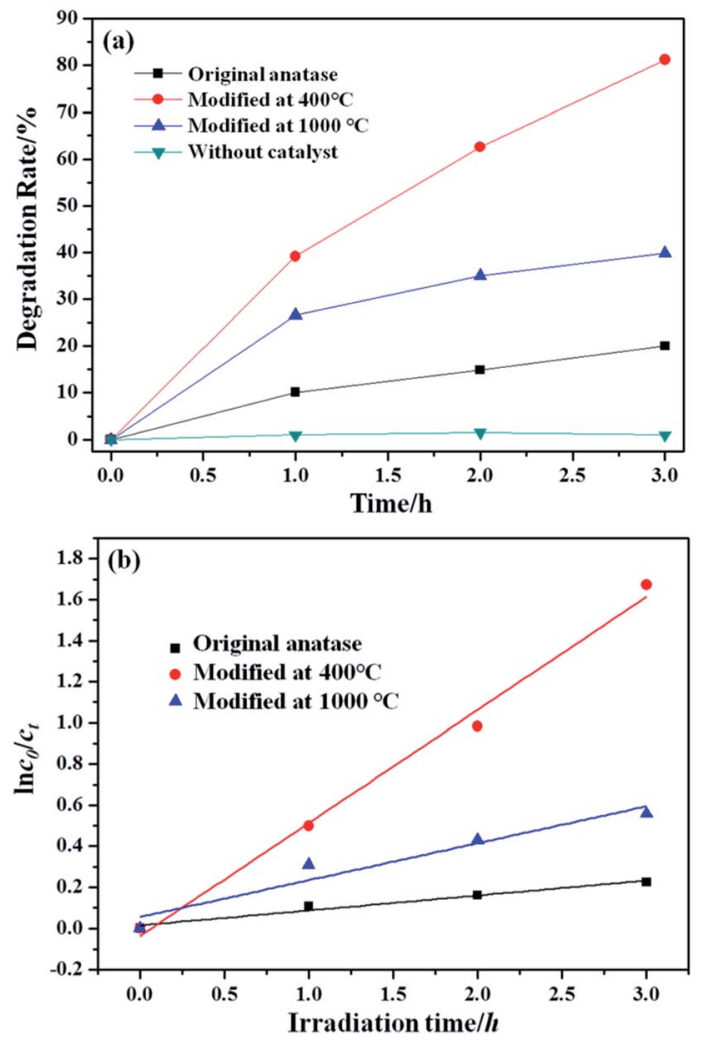

Fig. 7 (a) Degradation rate of samples before and after heat treatment in vacuum; (b) photocatalytic degradation kinetics of $\mathrm{MO}$.

photocatalytic degradation reaction was in accorded with firstorder kinetic. The $\mathrm{TiO}_{2}$ treated at $400{ }^{\circ} \mathrm{C}$ had the highest $k_{\mathrm{e}}$, where the value of $0.550 \mathrm{~h}^{-1}$ was acquired.

\section{Formation mechanism of non-stoichiometric compound $\mathrm{TiO}_{2-x}$}

Both the HRTEM analysis and XPS analysis show that the oxygen vacancy defects were introduced into the lattice of nano$\mathrm{TiO}_{2}$ after heat treatment in vacuum. The atomic ratios of $\mathrm{O} / \mathrm{Ti}$ in samples modified at $400{ }^{\circ} \mathrm{C}$ and $1000{ }^{\circ} \mathrm{C}$, respectively, were 1.9337 and 1.9390, implying that the non-stoichiometric compound $\mathrm{TiO}_{2-x}$ was formed. This section focuses on the mechanism of the formation of the non-stoichiometric compound $\mathrm{TiO}_{2-x}$.

By the non-stoichiometric compound, it refers to the compound in which the proportion between the negative ions and positive ions is not constant. Such non-stoichiometric compound can be considered as a solid solution of a highvalence compound and a low-valence compound, it could also

Table 3 Parameters of the photocatalytic degradation kinetics

\begin{tabular}{lcc}
\hline Catalysts & $k_{\mathrm{e}}\left(\mathrm{h}^{-1}\right)$ & $R^{2}$ \\
\hline Anatase & 0.073 & 0.964 \\
Modified at $400{ }^{\circ} \mathrm{C}$ & 0.550 & 0.989 \\
Modified at $1000{ }^{\circ} \mathrm{C}$ & 0.180 & 0.912
\end{tabular}


be considered as a point defect. ${ }^{41}$ In general, the formation of non-stoichiometric compounds is related to the atmosphere, pressure, and temperature. During the heat treatment in vacuum, not only the oxygen adsorbed on the surface of $\mathrm{TiO}_{2}$ was desorbed but also the oxygen atoms in the lattice of $\mathrm{TiO}_{2}$ diffused to the vacuum due to the lack of oxygen in the environment, leading to the formation of the oxygen vacancies and some $\mathrm{Ti}^{4+}$ ions were reduced to $\mathrm{Ti}^{3+}$ ions to keep the electric neutrality. The narrow scanning on element Ti also confirms the formation of $\mathrm{Ti}^{3+}$ ions. The specific reaction of the formation of $\mathrm{TiO}_{2-x}$ can be expressed as follows. Note that in oxygenfree environments, the reaction of $\mathrm{TiO}_{2}$ is:

$$
\begin{gathered}
2 \mathrm{TiO}_{2}-\frac{1}{2} \mathrm{O}_{2}=2 \mathrm{Ti}_{\mathrm{Ti}}^{\prime}+V_{0}^{*}+3 \mathrm{O}_{0} \\
2 \mathrm{Ti}_{\mathrm{Ti}}+\mathrm{O}_{0}=2 \mathrm{Ti}_{\mathrm{Ti}}^{\prime}+V_{0}^{*}+\frac{1}{2} \mathrm{O}_{2} \uparrow
\end{gathered}
$$

Since $\mathrm{Ti}_{\mathrm{Ti}}^{\prime}=\mathrm{Ti}_{\mathrm{Ti}}+\mathrm{e}^{\prime}$, we then derive from (2) and (3) that

$$
\mathrm{O}_{0}=2 \mathrm{e}^{\prime}+V_{0}^{*}+\frac{1}{2} \mathrm{O}_{2} \uparrow
$$

This defect reaction can be divided into the following types:

$$
\begin{array}{rlrl}
\mathrm{O}_{0} \rightleftharpoons V_{0}^{\circ}+\frac{1}{2} \mathrm{O}_{2} \uparrow, & & k_{1}=\left[V_{0}^{\circ}\right] P_{\mathrm{O}_{2}}{ }^{1 / 2} \\
V_{0}^{\circ} \rightleftharpoons V_{0}^{*}+\mathrm{e}^{\prime}, & k_{2}=\left[V_{0}^{*}\right] n /\left[V_{0}^{\circ}\right], \\
V_{0}^{*} \rightleftharpoons V_{0}^{*}+\mathrm{e}^{\prime}, & & k_{2}=\left[V_{0}^{*}\right] n /\left[V_{0}^{*}\right],
\end{array}
$$

where $n=\left[V_{0}^{*}\right]-2\left[V_{0}^{*}\right]$ denotes the condition of electrical neutrality.

Case 1: suppose that $V_{0}^{\circ} \gg V_{0}^{*}+\left[V_{0}^{* *}\right]$, it then holds that $V_{0}^{\circ}=k_{1} P_{\mathrm{O}_{2}}{ }^{-1 / 2}$;

Case 2: suppose that $V_{0}^{*} \rightleftharpoons V_{0}^{\circ}+\left[V_{0}^{*}\right]$, then the condition of electrical neutrality is approximately equal to $n=\left[V_{0}^{*}\right]$, and further, it holds that $n=\left[V_{0}^{*}\right]=\left(k_{1} k_{2}\right)^{1 / 2} P_{\mathrm{O}_{2}}{ }^{-1 / 4}$;

Case 3: suppose that $V_{0}^{* *} \gg V_{0}^{\circ}+\left[V_{0}^{*}\right]$, then the condition of electrical neutrality is approximately equal to $n=2\left[V_{0}^{*}\right]$, and further, it holds that $\left[V_{0}^{*}\right]=\left(\frac{1}{4} k_{1} k_{2} k_{3}\right)^{1 / 3} P_{\mathrm{O}_{2}}{ }^{-1 / 6}$.

It is worth mentioning that the oxygen partial pressure is relatively low and the corresponding is relatively large under the heat treatment in vacuum. As a result, defect reaction belongs to the third case. Hence, the concentration of the oxygen vacancy is inversely proportional to the power of the oxygen partial pressure.

The mechanism of the effect of oxygen vacancy defects on the application of nano- $\mathrm{TiO}_{2}$ under visible light.

The oxygen vacancies of the anatase nano- $\mathrm{TiO}_{2}$ obtained by the heat treatment in vacuum are positively charged, and two electrons are bounded nearly to the oxygen vacancy. The two electrons are different from the general free electrons in that they are quasi-free electrons bounded by the oxygen vacancies. If they associated with the $\mathrm{Ti}^{4+}$ nearby, this kind of electrons would make $\mathrm{Ti}^{4+}$ ions into $\mathrm{Ti}^{3+}$ ions. If in an electric field, this kind of electron may migrate from one $\mathrm{Ti}^{4+}$ ion to another $\mathrm{Ti}^{4+}$ ion nearby such that electronic conductivity is formed. The material with such a defect is called a n-type semiconductor. This kind of negative-ion vacancy together with the surrounding bounded excess electrons is called the color structure, in the center of which the electrons can absorb light of a certain wavelength, as illustrated in Fig. 8.

In the existing work, the introduction of the oxygen vacancy defects to the crystal structure of nano- $\mathrm{TiO}_{2}$ is mainly by nonmetallic elements doping. By introducing the oxygen vacancy to the crystal structure of $\mathrm{TiO}_{2}$, the non-metallic elements then can substitute the oxygen vacancy, such that $\mathrm{TiO}_{2-x} \mathrm{~A}_{x}$ (A denotes the nonmetallic element) crystal is formed. In this case, the band gap of the nonmetallic elements doped $\mathrm{TiO}_{2}$ is narrow and an obvious redshift of the threshold of optical absorption will occur. The obvious redshift then results in extended the response range of absorbed light.

In this work, the oxygen vacancies formed in the crystal structure of $\mathrm{TiO}_{2}$ do not introduce other elements into the lattice of $\mathrm{TiO}_{2}$. In regard to the existence of oxygen vacancies in the band structure of $\mathrm{TiO}_{2}$, some scholars have measured the energy of the electron detaching from the oxygen vacancy in $\mathrm{TiO}_{2}$. They claimed that the energy value is between 0.75 and $1.8 \mathrm{eV},{ }^{42}$ and the oxygen vacancy of anatase $\mathrm{TiO}_{2}$ is located at 2.02-2.45 eV above the valence band. In addition, the isolated oxygen vacancy in the band structure of $\mathrm{TiO}_{2}$ is between the valence band and conduction band, as can be seen from Fig. 9. Generally, photoexcitation process in light is only one step. However, for the $\mathrm{TiO}_{2}$ with oxygen vacancy, the oxygen vacancy

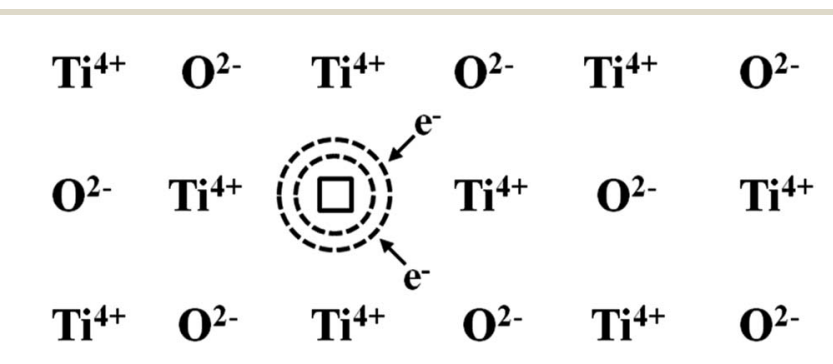

Fig. 8 Defect structure of $\mathrm{TiO}_{2-x}$.

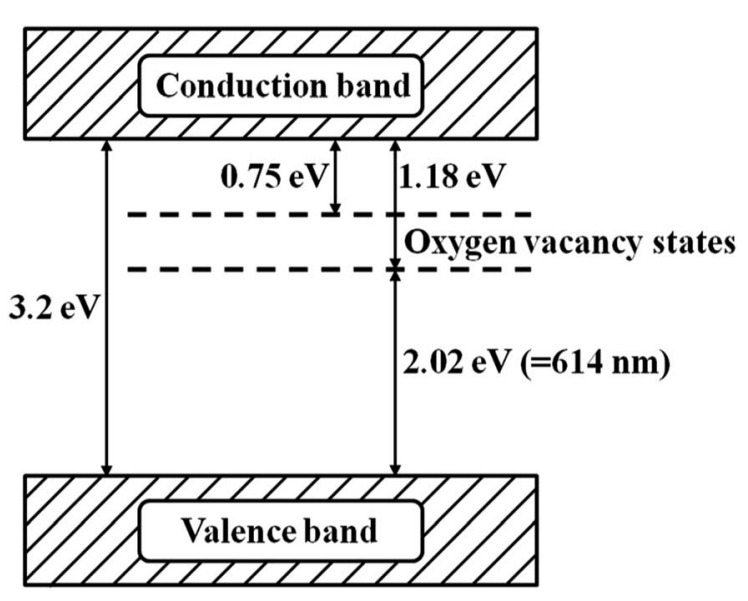

Fig. 9 The band structure model for the anatase $\mathrm{TiO}_{2}$ with oxygen vacancies. 
state would be involved in a new photoexcitation process in light. That is, the electrons on the valence band are excited with the low energy provided by visible light. The excited electrons jump to the oxygen vacant state and then to the conduction band of $\mathrm{TiO}_{2}$ such that the visible light is absorbed.

\section{Conclusions}

(1) The oxygen vacancy and $\mathrm{Ti}^{3+}$ were formed in the crystal structure of nano- $\mathrm{TiO}_{2}$ after heat treatment in vacuum, in which the oxygen vacancy located between the valence band and the conduction band of the energy band structure of nano- $\mathrm{TiO}_{2}$. This makes the photo-generated electrons first jump into the state of oxygen vacancy under the effect of lower energy and then to the conduction band, such that the visible-light absorption is improved.

(2) The nano- $\mathrm{TiO}_{2}$ samples can absorb the visible light of certain wavelength after heat treatment in vacuum. The wavelengths of light the nano- $\mathrm{TiO}_{2}$ absorbs is shifted to the visible portion of the spectrum. Specifically, the optical absorption threshold wavelength of the samples modified at $400{ }^{\circ} \mathrm{C}$ and $1000{ }^{\circ} \mathrm{C}$ were shifted to $480 \mathrm{~nm}$ and $600 \mathrm{~nm}$, respectively, after the heat treatment in vacuum.

(3) The modified samples possess visible light catalytic activity, and the degradation rate of the powders after heat treatment in vacuum at $400{ }^{\circ} \mathrm{C}$ is $81.233 \%$ after 3 hour light exposure.

\section{Conflicts of interest}

There are no conflicts to declare.

\section{Acknowledgements}

This work was supported by the Project of Basic Science and Frontier Technology Research Project of Chongqing (cstc2017jcyjAX0310, cstc2016jcyjA0561, cstc2014jcyjA50025); Scientific and Technological Research Program of Nanchuan in Chongqing (CX201407); Science and Technology Research Program of Chongqing Municipal Education Commission (KJ1705124); Research Program of Chongqing Jiaotong University (16JDKJC-A005).

\section{Notes and references}

1 A. Fujishima and K. Honda, J. Nat., 1972, 238, 37.

2 I. Ali, M. Suhail, Z. A. Alothman and A. Alwarthan, RSC Adv., 2018, 8, 30125.

3 Y.-W. Su, W.-H. Lin, Y.-J. Hsu and K.-H. Wei, Small, 2014, 10, 4427.

4 Y.-H. Chiu and Y.-J. Hsu, Nano Energy, 2017, 31, 286.

5 P.-Y. Hsieh, Y.-H. Chiu, T.-H. Lai, M.-J. Fang, Y.-T. Wang and

Y.-J. Hsu, ACS Appl. Mater. Interfaces, 2019, 11, 3006.

6 Y.-H. Chiu, T.-H. Lai, C.-Y. Chen, P.-Y. Hsieh, K. Ozasa, M. Niinomi, K. Okada, T.-F. M. Chang, N. Matsushita, M. Sone and Y.-J. Hsu, ACS Appl. Mater. Interfaces, 2018, 10, 22997.
7 Y.-S. Chang, M. Choi, M. Baek, P.-Y. Hsieh, K. Yong and Y.-J. Hsu, Appl. Catal., B, 2018, 225, 379.

8 Y.-C. Pu, Y. Ling, K.-D. Chang, C.-M. Liu, J. Z. Zhang, Y.-J. Hsu and Y. Li, J. Phys. Chem. C, 2014, 118, 15086.

9 Y.-C. Pu, G. Wang, K.-D. Chang, Y. Ling, Y.-K. Lin, B. C. Fitzmorris, C.-M. Liu, X. Lu, Y. Tong, J. Z. Zhang, Y.-J. Hsu and Y. Li, Nano Lett., 2013, 13, 3817.

10 A. A. Valeeva, I. B. Dorosheva, E. A. Kozlova, R. V. Kamalov, A. S. Vokhmintsev, D. S. Selishchev, A. A. Saraev, E. Y. Gerasimov, I. A. Weinstein and A. A. Rempel, J. Alloys Compd., 2019, 796, 293.

11 R. Huang, S. Zhang, J. Ding, Y. Meng, Q. Zhong, D. Kong and C. Gu, J. Colloid Interface Sci., 2019, 553, 647.

12 Y.-H. Chiu, T.-F. M. Chang, C.-Y. Chen, M. Sone and Y.-J. Hsu, Catalysts, 2019, 9, 430.

13 J.-B. Chemin, S. Bulou, K. Baba, C. Fontaine, T. Sindzingre, N. D. Boscher and P. Choquet, Sci. Rep., 2018, 8, 9603.

14 G. Chen, S. Ouyang, Y. Deng, M. Chen, Y. Zhao, W. Zou and Q. Zhao, RSC Adv., 2019, 9, 18652.

15 X. Shen, F. Zhang, K. Li, C. Qin, P. Ma, L. Dai and K. Cai, Mater. Des., 2016, 92, 1007.

16 Z. Yuan, S. Huang, S. Lan, H. Xiong, B. Tao, Y. Ding, Y. Liu, P. Liu and K. Cai, J. Mater. Chem. B, 2018, 6, 8090.

17 L. Sutrisno, Y. Hu, X. Shen, M. Li, Z. Luo, L. Dai, S. Wang, J. L. Zhong and K. Cai, Mater. Sci. Eng., C, 2018, 89, 95.

18 B. Tao, Y. Deng, L. Song, W. Ma, Y. Qian, C. Lin, Z. Yuan, L. Lu, M. Chen, X. Yang and K. Cai, Colloids Surf., B, 2019, 177, 242.

19 J.-M. Li, C.-W. Tsao, M.-J. Fang, C.-C. Chen, C.-W. Liu and Y.-J. Hsu, ACS Appl. Nano Mater., 2018, 1, 6843.

20 J.-M. Li, Y.-T. Wang and Y.-J. Hsu, Electrochim. Acta, 2018, 267, 141.

21 M. Samiee and J. Luo, Mater. Lett., 2013, 98, 205.

22 H. Yamashita, M. Harada, J. Misaka, M. Takeuchi, B. Neppolian and M. Anpo, Catal. Today, 2003, 84, 191.

23 S. Sato, R. Nakamura and S. Abe, Appl. Catal., A, 2005, 284, 131.

24 D. Li, H. Haneda, S. Hishita, N. Ohashi and N. K. Labhsetwar, J. Fluorine Chem., 2005, 126, 69.

25 D. Li, H. Haneda, N. K. Labhsetwar, S. Hishita and N. Ohashi, Chem. Phys. Lett., 2005, 401, 579.

26 J. Zhang, L. J. Xu, Z. Q. Zhu and Q. J. Liu, Mater. Res. Bull., 2015, 70, 358.

27 D. R. Zhang, H. L. Liu, S. Y. Han and W. X. Piao, J. Ind. Eng. Chem., 2013, 19, 1838.

28 W. H. Cheng, C. D. Li, X. Ma, L. M. Yu and G. Y. Liu, Mater. Des., 2017, 126, 155.

29 Y. Q. Zhang and P. J. Li, Mater. Des., 2015, 88, 1250.

30 V. Subramanian, E. Wolf and P. V. Kamat, J. Phys. Chem. B, 2001, 105, 11439.

31 Y. X. Zhang, H. Ma, M. Yi, Z. G. Shen, X. Z. Yu and X. J. Zhang, Mater. Des., 2017, 125, 94.

32 G. L. Zhao, H. Kozuka and T. Yoko, J. Ceram. Soc. Jpn., 1996, 104, 164.

33 G. Colon, M. C. Hidalgo, G. Munuera, I. Ferino, M. G. Cutrufello and J. A. Navío, Appl. Catal., B, 2006, 63, 45. 
34 G. Colon, M. C. Hidalgo and J. A. Navio, Appl. Catal., B, 2009, 90, 633.

35 L. L. Lai, W. Wen, B. Fu, X. Y. Qian, J. B. Liu and J. M. Wu, Mater. Des., 2016, 108, 581.

36 R. Asahi, T. Morikawa, T. Ohwaki, K. Aoki and Y. Taga, Science, 2001, 293, 269.

37 R. Saravanan, D. Manoj, J. Qin, M. Naushad, F. Gracia, A. F. Lee, M. M. Khan and M. A. Gracia-Pinilla, Process Saf. Environ. Prot., 2018, 120, 339.
38 L. Lu, R. Shan, Y. Shi, S. Wang and H. Yuan, Chemosphere, 2019, 222, 391.

39 X. Yuan, X. Wu, Z. Feng, W. Jia, X. Zheng and C. Li, Catalysts, 2019, 9, 624.

40 W. J. Yin, B. Wen, C. Zhou, A. Selloni and L. M. Liu, Surf. Sci. Rep., 2018, 73, 58.

41 L. M. Zhang, X. H. Huang and X. L. Song, Materials science foundation, Wuhan University Press, Wuhan, 2004, p. 155.

42 D. C. Cronemeyer, Phys. Rev., 1959, 113, 1222. 